Fecha de recepción: julio 2014 Fecha de aceptación: marzo 2015 Versión final: marzo 2016

\section{Moda, cuerpo e industria. Una revisión sobre la industria de la moda, el uso generalizado de TICs y la Tercera Revolución Industrial Informacional}

Esteban Maioli *

\begin{abstract}
Resumen: El siglo XX es testigo y escenario de múltiples cambios políticos, económicos, sociales y culturales impulsados por las transformaciones en el plano tecnológico y científico. Éstos implican la aceleración de los tiempos y con ellos, grandes modificaciones en los usos y costumbres de la sociedad. La moda, como manifestación de la cultura, no quedará exenta de esas transformaciones y será expresión de los nuevos vientos de cambio. Con los movimientos artísticos como aliados, la irrupción de nuevos actores como las mujeres y los jóvenes en la escena social, el impulso de los medios masivos de comunicación y por impacto de la globalización, entre otras variables, la moda adquirirá dimensiones impensadas; y con avances y retrocesos, se consolidará como una industria con sus propias leyes y dinámica. Recorrer parte de esos escenarios del siglo XX será el objetivo del presente cuaderno, invitando a reflexionar sobre esos cien años que cambiaron la historia.
\end{abstract}

Palabras clave: moda - cultura - sociedad - transformaciones sociales - arte - mass media.

[Resúmenes en inglés y portugués en las páginas 97-98]

${ }^{(*)}$ Licenciado en Ciencia Política (UBA). Magíster en Ciencia Política y Sociología (FLACSO Sede Académica Argentina). Doctorando en Ciencias Sociales (FLACSO Sede Académica Argentina). Docente en Universidades públicas y privadas del país.

\title{
Introducción
}

La moda y el cuerpo son, sin lugar a dudas, dos temas sobre los cuales la disciplina sociológica ha producido enorme cantidad de materiales para su elucidación y reflexión. La moda es un fenómeno social que ha llamado la atención de casi todos los grandes representantes de la teoría sociológica, ya desde su etapa clásica de conformación. No obstante, pocos han dirigido sus esfuerzos por realizar estudios específicos sobre sus dinámicas. Algo similar ha sucedido con el cuerpo. La mayoría de las teorías sociológicas lo suponen, pero no muchas han considerado al cuerpo un objeto de conocimiento sociológico en sí mismo. Sin embargo, desde hace una buena cantidad de años, al menos veinte, cada vez son más los especialistas que dedican sus investigaciones a temas relacionados con la moda, el cuerpo, y las interesantes vinculaciones que aparecen entre ellos. 
El presente artículo pretende revisar algunos aspectos significativos de la vinculación entre moda y cuerpo. Dicha relación puede asumir múltiples modalidades, alcances y formas. Por ello, en virtud de problematizar la relación que asume estos dos objetos sociológicos en el contexto histórico actual, se intentará analizar la moda y el cuerpo en relación con las implicaciones de la producción económica de las prendas de vestir en el contexto más amplio de la sociedad industrial informacional.

En este sentido, tal como afirma Saulquin:

Es indudable que existe una estrecha relación entre la construcción del sistema de las apariencias, y las necesidades, especialmente económicas y políticas, que tienen las sociedades en sus distintas etapas históricas. Así, la simbiosis que se generan entre el vestido y el cuerpo, la sociedad y la naturaleza, van a conformar discursos coherentes para enfatizar esas diferentes necesidades sociales. (Saulquin, 2001, p. 1)

$\mathrm{Al}$ igual que en otras áreas de la producción de bienes, la moda ha transitado el camino de una producción basada en modelos clásicos, de diseño fordista, hacia una producción basada en el modelo más contemporáneo del "just in time" (JIT). Ciertamente, tal pasaje se debe a ciertas modificaciones primordiales acaecidas en el sistema productivo global, del cual es necesario dar cuenta siempre que se intente resaltar los aspectos productivos del fenómeno de la moda. En principio, es posible verificar que el vestido (entendido éste como toda prenda de vestir, tanto para varón como mujer) ha pasado de un formato "homogeneizado" hacia un formato novedoso, que permite expresar el cambiante gusto de los potenciales compradores. La producción fordista de prendas suponía la elaboración en serie de una enorme cantidad de prendas, stock de importante volumen que era incapaz de contemplar la individualidad de los consumidores finales de las mismas. En cambio, el modelo JIT, asistido por las tecnologías de la información y la comunicación (TICs), es capaz de satisfacer esta nueva serie de demandas sin que ello signifique pérdidas de rentabilidad para el productor de estos bienes. De esta manera, el vestido que había obligado al cuerpo a achatarse, aplanarse, homogeneizarse, encuentra ahora en el nuevo modelo de producción, las posibilidades de expresión de una nueva y significativa relación entre el cuerpo y el vestido.

Hasta alrededor del siglo XIV, las vestimentas masculinas y femeninas no representaban las diferencias sexuales de modo revelador. A partir de entonces, comienzan a exhibirse las diferencias: el traje se angosta, y el corto es utilizado por el hombre, mientras que el largo es reservado a las mujeres. A lo largo del complejo proceso de desarticulación medieval, el desarrollo del humanismo y la concomitante revolución comercial, provocan que el hombre comience a centrar la mirada en sí mismo, y por tal motivo, que descubra el propio cuerpo. Algunos especialistas (Liqueur, 1992) acuerdan en considerar que la falta de representación del género masculino y femenino en forma diferenciada en el vestido antes del siglo XIV se debió, principalmente, a esta falta de reconocimiento del propio cuerpo. Tal falta de reconocimiento también puede encontrarse en la limitación del mismo lenguaje. Liqueur (1992) afirma que el lenguaje del cuerpo era unisexual, y por lo tanto, la diferencia corporal siempre amenazaba con tornarse semejanza; el concepto de cuerpo 
masculino era el prototipo de la forma humana, debido a la existencia de un lenguaje que limitaba la percepción de las diferencias.

En este sentido, no es casual que en pleno Renacimiento se interrelacionen hechos tales como la aparición del fenómeno de la moda a partir de la correlación de cuerpo femenino y masculino, el surgimiento de la idea de pudor (hacia el siglo XV) y el desarrollo lingüístico que ahora es capaz de especificar el aparato genital femenino. La idea del pudor, por cierto, una de las motivaciones más importantes del vestido, a su vez, hace su aparición en el momento del abandono de la vestimenta ritual a favor de un vestido que, amparado en la misma lógica de la moda y las leyes suntuarias, favorecía la visualización de las diferencias sociales. Por ello, es necesario resaltar un hecho significativo de la moda como fenómeno social: la misma, en tanto supone esta doble actividad de "mostrar" y ocultar", será una vía adecuada de expresión de las profundas transformaciones que se desarrollaban en aquellas épocas en los sistemas de estratificación social.

En este punto, es posible argumentar junto con Saulquin que:

El vestido pasaba a convertirse entonces en una evidente señalización de esas diferencias y del lugar que se ocupaba en la escala social. El, hasta ese momento, vestido estable para ambos sexos, empieza a subrayar con la aparición de la moda en el siglo XIV, las diferencias sexuales en abultados muslos, brazos y braguetas en los hombres, mientras las mujeres enfatizaban sus caderas, vientres y pechos. Esta exaltación de las diferencias sexuales, que podría parecer en primera instancia como una celebración del cuerpo y sus funciones, resultaba más bien una representación de las recién estrenadas diferencias. (Saulquin, 2001, p. 19)

Es así como las vestimentas mostraban con la moda su creciente poder, al negar y esconder un cuerpo que transformaban en mero soporte. Tal vez el verdugado, el corsé y los extravagantes cuellos rizados de muselina almidonada, que hacen su aparición en la España del siglo XVI, se muestren como un buen ejemplo de distancia y ocultamiento del cuerpo, durante la llamada etapa aristocrática de la moda.

Por su parte, la consolidación del capitalismo, que necesitaba dar salida a la creciente acumulación de tejidos industriales, va a complicar los diseños femeninos tanto interiores como exteriores, que llegaron a emplear, a partir de 1850, hasta cuarenta metros de telas para su realización. Era esperable, por tanto, que ese cuerpo sepultado por cantidad de telas, debiera luchar para imponer sus formas bajo la tutela de apretadísimos corsés. Ya el pragmatismo norteamericano había inventado hacia 1830 los ojalillos metálicos, que facilitaban el ajuste máximo del cuerpo. A partir de ese entonces, y hasta la finalización de la segunda década del siglo XX, la sociedad industrial va a castigar al cuerpo para destacar la supremacía de poder de un vestido conformado según las tendencias de la moda.

Los intereses de la sociedad industrial demostraron una vez más que las estrechas relaciones que existen entre la visión del mundo y la forma de percibir el cuerpo. "Desde una visión mecanicista, la naturaleza convertida en una fuente inagotable de recursos y prestaciones servía de modelo a una percepción del cuerpo como objeto económico". (Saulquin, 2001, p. 34) 
Con la consolidación de la cultura de masas, ya en los años '60, la importancia de las categorías femeninas y masculinas resignan su importancia a favor de nuevas y más significativas categorías: la juventud y la madurez. A partir de ese momento, e incluso hasta la actualidad, la imagen juvenil se asocia con el máximo prestigio en una estructura sociocultural que privilegia los "cuerpos jóvenes". Sin embargo, existen algunos indicios que muestran un cambio sociocultural en curso, aún de modo muy incipiente. De modo más reciente, se ha comenzado a enfatizar algunas nuevas ideas, tales como la salud y la calidad de vida. En este sentido, existe un cambio que es advertible en términos de generación histórica. De esta forma, es posible pensarse una desarticulación de la relación cuerpo-soporte con un vestido que asume su forma de acuerdo a los dictados de la moda. Las nuevas formas del vestido serán proyectadas en torno a la conformación de una topología corporal que es pensada en constante movimiento. Es posible pensar, en consecuencia, que esta nueva relación generará los impulsos necesarios, al mismo tiempo que será una consecuencia necesaria, de modificaciones y re-significaciones del discurso global de la apariencia. Es advertible, en principio al menos, una creciente dilución de las preeminencias y alternancias, según las cambiantes épocas, del vestido en detrimento del cuerpo, y viceversa. ¿Es posible pensar que la piel no será el límite biológico entre el vestido y el soporte corporal? ¿Es dable pensar que las tecnologías de la virtualidad modifiquen los límites tradicionales de tiempo y espacio, en su permanente vinculación del individuo y la sociedad? ¿Puede la moda, como fenómeno sociocultural, operar como mecanismo de desenclave? (Giddens, 1998) En términos del análisis ofrecido por Saulquin (2001), en la actualidad, la funcionalidad del vestido se acentúa de tal manera que la forma de definir un material de uso es también una manera de indicar las prestaciones que puede ofrecer. Esto ocurre de este modo porque en la sociedad actual, caracterizada por la globalización social y su creciente aceleración temporal, la vestimenta comienza a resignar la función principal, y otrora exclusiva, de indicador social de las diferencias estratificacionales. En cambio, el vestido asume nuevas funciones, tales como el cumplimiento y la satisfacción de requerimientos más específicos para los cuales fue diseñada. Por ello, las tecnologías aplicadas a la investigación y desarrollo de nuevos materiales se encuentran sumamente desarrolladas. Son estas nuevas texturas las que tendrán ahora un lugar preferencial, en tanto responden al nuevo imaginario social que concentra su atención en la sustentabilidad y el cuidado medio-ambiental.

El artículo que aquí se presenta pretende realizar una revisión sucinta sobre algunas conceptualizaciones primordiales sobre moda, cuerpo y producción, todas ellas desde el enfoque sociológico. El interés primigenio de esta reflexión se concentra en conocer como el sistema de la moda se articula con el sistema productivo en el marco de la actual fase del desarrollo del capitalismo moderno, al que podemos llamar Tercera Revolución Industrial-Informacional. En el marco específico de desarrollo de este modo productivo, las grandes compañías de la industria del vestido se apropian y hacen uso de las tecnologías de la información y la comunicación para alcanzar una configuración espacio-temporal intensificada. Tales grandes compañías pueden servir de ejemplo para dar cuenta de una nueva división social del trabajo a nivel global que opera para un tipo específico de empresa: la compañía transnacional.

Este tema resulta de especial interés para dar cuenta del debate actual en torno al uso de las tecnologías de la información y la comunicación (en adelante, TICs) en las con- 
figuraciones socioculturales actuales, generalmente caracterizadas como "sociedades del conocimiento" o "sociedades de la información". Al igual que otros estudios de caso en el ámbito industrial (la literatura socio-económica sobre esta temática es sumamente vasta), la industria del vestido puede ser un puntapié inicial adecuado para ejecutar una reflexión más profunda sobre aspectos éticos del desarrollo económico y la consecución de lo que Jaggar llama "la sociedad buena”. (Jaggar, 1983)

\section{Acerca de la moda y el cuerpo}

La moda ha sido objeto de reflexión e indagación desde hace años por las más variadas escuelas de pensamiento de la tradición sociológica. Ya en la etapa de consolidación de la Sociología como nueva ciencia social, Simmel era el primero de los sociólogos "clásicos" que realizaba alguna meditación sociológica sobre la moda. Sin embargo, no siempre ha sido considerada como un tema central del cual se pudieran obtener conclusiones aplicables a todo el tejido social. Sin embargo, durante el siglo XX, autores de las más diversas vertientes disciplinares y teóricas han reflexionado sobre la moda. Pensadores de la talla del ya mencionado Simmel, Flügel, Lipovetsky o Barthes, han utilizado a la moda como objeto que merece un análisis científico, y en virtud de ello, se ha conformado en objeto de estudio y análisis. Simmel consideraba que la moda podía ser pensada como una forma social, y por ello, como expresión de la vida social misma. Tal vida implica la ocurrencia de procesos sociales constitutivos, tales como la diferenciación social o la estructuración. En tanto todos los seres humanos se reconocen diferentes, necesitan de la imitación de la vida de los otros para disminuir la angustia de la soledad y la exigencia de la permanente elección "racional" de sus modos de comportamiento social. Por ello, Simmel entendía que la moda es:

La imitación de un modelo dado que proporciona así satisfacción a la necesidad de apoyo social; conduce al individuo al mismo camino por el que todos transitan y facilita una pauta general que hace de la conducta de cada uno un mero ejemplo de ella. (Simmel, 1988, p. 28)

La moda expresa, pues, al igual que otras formas sociales, el sometimiento del hombre a un permanente proceso de cambio y mutación. De este modo, las clases superiores, en su permanente pretensión de diferenciación social, serán los motores del cambio de la moda, en tanto que en cuanto las clases inferiores logren identificarse con las superiores, se activarán los mecanismos de diferenciación nuevamente. Por ello la moda concentra tanto la identificación como la diferenciación, y por ello es expresión de la vida social.

La moda puede ser concebida como una forma particular de lenguaje. Croci y Vitale (2000) afirman que:

La lógica de la moda, considerada como producción de signos distintivos que en cuento dejan de serlo, deben ser cambiados en el reino de lo efímero, es requerida por una sociedad de consumo que reclama la creación de nuevas necesidades para seguir existiendo. (Croci y Vitale, 2000, p. 6) 
En este sentido, la moda se entreteje en la compleja dinámica del consumo y de la creación de orientaciones motivacionales para la acción que no encuentran su sustento en la satisfacción de necesidades básicas. (Bauman, 2010)

En tanto lenguaje, la moda ha sido objeto de reflexión por parte de la semiología. En esta área disciplinar, los aportes de Barthes (2003) resultan de especial significación. El pensador francés considera que la moda es pasible de un análisis semántico. "La moda edifica un sistema muy estricto de signos, mira de dar a esos signos la apariencia de puras razones; $y$ precisamente porque la moda es tiránica y su signo arbitrario, debe convertirlo en hecho natural o en ley racional: la connotación no gratuita dentro de la economía general del sistema, tiene la función de restaurar una determinada ratio. (Barthes, 2003: 185)

En este sentido, el carácter tiránico de la moda se vincula con su carácter de hecho social. Tal como afirmaba Durkheim, la moda resulta ser un hecho social, que supone ciertas formas de actuar, sentir y pensar de una colectividad de individuos. Los hechos sociales (y por ello, la moda) comporta la característica de la coerción, en tanto establece condicionamientos a nuestras formas de comportamiento, percepción y cognición, si bien tales condiciones no son vividas subjetivamente como tiránicas. No obstante Barthes advierte que en cuanto la moda encuentra canales legitimados de comunicación con diversos públicos, su carácter tiránico se magnifica. Sirva de ejemplo la situación hipotética de una revista de moda que, al pie de una cierta fotografía señala "últimas tendencias para salir por la noche". En forma casi automática, todo aquello contenido en la fotografía será considerado "de moda". Barthes advierte que el carácter tiránico asume una doble lectura: por un lado, aquel que no se adecue a lo propuesto queda por fuera del sistema de la moda; por otro lado, la adopción de aquello propuesto implica también la legitimación y objetivación de un status-rol determinado. Por ello, la moda puede y debe ser comprendida también como dispositivo ideológico que asigna roles y funciones dentro del aparato social. En este punto, las posturas feministas han advertido sobre las asimetrías de género que el sistema de la moda produce y reproduce. Barthes señala que:

La moda se esfuerza en trazar correspondencias entre el vestido descrito y unos usos, unos caracteres, unas estaciones, unas funciones: un vestido para la noche, para ir de compras, para la primavera (...). En este caso, la arbitrariedad de la moda se elude y enmascara bajo este léxico racionalista, naturalista. La moda miente. Se oculta detrás de coartadas sociales o psicológicas. (Barthes, 2003, p. 430)

Lurie (1994) también analiza la moda desde un punto de vista semiológico. De modo similar a Barthes, la pensadora considera que la moda conforma un sistema de signos, un lenguaje excepcional. La particularidad de este lenguaje, considera, consiste en la falta de necesidad de lenguaje oral para poder transmitir un mensaje. La mera interacción social implica un intercambio de mensajes, todos ellos anclados en los modos de vestir. Una persona construirá ciertas presuposiciones sobre "el otro", tales como edad, sexo, ocupación, nivel socio-económico; probablemente podrá esbozar alguna idea sobre estados de ánimo, procedencia, gustos, opiniones e incluso gustos y deseos sexuales. La moda cuenta con indumentarias, todas ellas consideradas como palabras en este sistema de signos; "del 
mismo que el hablante medio de cualquier idioma conoce muchas más palabras de las que suele usar en la conversación, todos somos capaces de comprender el significado de estilos de ropa que nunca nos vamos a poner". (Lurie, 1994, p. 188)

Durante décadas, los modos en los cuales se ha reflexionado sobre la moda estuvieron ligados con la historia del vestido, al punto tal que se la pensó con relación a sus cambios y transformaciones a lo largo de los años. Lipovetsky considera que "la moda se halla al mando de nuestras sociedades; en menos de medio siglo, la seducción y lo efímero han llegado a convertirse en los principios organizativos de la vida colectiva moderna" (Lipovetsky, 2004, p. 13). La moda es pensada como fenómeno moderno; se la puede ubicar hacia el momento de emergencia de la secularización social. La postura del pensador francés discute con posiciones sociológicas más clásicas, como la de Simmel. El sociólogo alemán entiende que la moda es una forma social, y por ello, es posible que sea ubicada en los orígenes mismos de la vida social. "En contra de la idea de que la moda es un fenómeno consustancial a la vida humano-social, se la afirma como un proceso excepcional, inseparable del nacimiento y desarrollo del mundo moderno occidental". (Lipovetsky, 2004: 23) El hecho de considerar la moda como fenómeno moderno implica dejar de lado concepciones antropológicas universalistas. Consiste en dejar de lado modos de cognición que entienden que la moda es una constante histórica. La moda es un fenómeno social moderno, y por ello, Lipovetsky lo vincula con la categoría de "lo efímero" en tanto que se inscribe en un momento socio-histórico de profundos cambios sociales. La modernidad supuso una reconversión radical de toda la estructura social.

El análisis de la Modernidad y su imbricación con la vida social ha sido objeto del conjunto de las ciencias sociales. Foucault ha sido uno de los autores que ha intentado caracterizar la sociedad moderna a partir de los dispositivos de poder y mecanismos de disciplinamiento aplicados sobre el cuerpo. Este tipo de reflexión cobra especial interés en tanto que:

Limitada al vestido o aplicada a todo el producto social, la moda puede ser pensada como un conjunto de técnicas y saberes que operan sobre el cuerpo y lo transforman en cuerpo productivo. En la sociedad que Foucault llama disciplinaria, el mecanismo de la moda exige que el cuerpo sea útil, entre otras cosas, como cuerpo consumidor. (Croci y Vitale, 2000: 6)

El cuerpo, por lo tanto, se convierte en objeto de conocimiento del saber sociológico, y comienza entonces a ser objeto de reflexión. Dicho cuerpo se encuentra influido por relaciones de poder y se encuentra inserto en estructuras de dominación. El cuerpo se inscribe en relaciones económicas y productivas y todo ello encuentra un reflejo más o menos transparente en los adminículos de la moda.

De los representantes de la teoría sociológica que concentra su atención en el cuerpo, probablemente sea Le Breton aquel que se ha esforzado más en poder sistematizar en una teorización coherente gran parte de lo escrito sobre el tema. En general, es posible considerar que el cuerpo ha sido objeto de una "sociología implícita", que no hacía referencia directa a los aspectos biológicos del ser humano; sin embargo, de modo creciente, una tradición anclada en la "sociología detallista", que dirige su mirada a la elaboración de elementos conceptuales específicos, está tomando forma y creciendo. 


\section{Modos de difusión de la moda}

Sin lugar a dudas, no de los fenómenos más estudiados por la Sociología especializada en el fenómeno sociocultural de la moda ha sido el proceso de difusión de la misma. El desarrollo de la vida social actual enfrenta a la teorización sociológica clásica al desafío de demostrar su capacidad explicativa frente a un contexto ciertamente novedoso. La caja de herramientas de la que se vale la Sociología estuvo caracterizada por el específico contexto socio-histórico en el cual la disciplina se ha desarrollado y consolidado. No obstante, la globalización cuestiona e interpela a la disciplina sociológica a discutir sus categorías de análisis fundamentales. En este sentido, las nuevas tecnologías de la información permiten que nuevos artículos, estilos y tendencias se difundan por el mundo con una rapidez inusitada y una facilidad nunca antes advertida.

Barreiro (2004) ha analizado en extenso los procesos de difusión de la moda. Siguiendo su análisis, es posible afirmar que la teoría sociológica ha generado dos grandes corrientes o vertientes de interpretación y análisis. La primera de ellas, formalizada por autores tan disímiles tales como Veblen, Braudillard o Bourdieu, considera que las innovaciones que se producen en el campo de la moda ( $y$ en el consumo, en general) tienen como objetivo principal la apropiación y uso de las clases "superiores". Una vez alcanzadas, el proceso de difusión consistiría en un "descenso" vertical de las clases altas a las más bajas (o inferiores). Veblen (1974) ha sido quien tal vez mejor ha analizado este proceso cuando analiza el consumo de lo que él llama la clase "ociosa", y en general puede ser caracterizado como sociedades pre-consumistas. Braudillard (1974) y el mismísimo Bourdieu (1991) han dedicado parte de sus estudios al análisis de las tendencias de consumo, arribando a conclusiones similares sobre sociedades consumistas. El planteo general consiste en entender que el proceso de difusión de la moda resulta de un fenómeno dependiente de la estructura de clases propia de la sociedad capitalista. Tal como afirma Barreiro, este fenómeno:

Se lo conoce también con la denominación "trickle-down effect"; se trata de un mecanismo que permite la difusión gota a gota de las modas, de los nuevos estilos de vida y del consumo en general, por el efecto que sobre los comportamientos tiene el sistema jerárquico de los status. (Barreiro, 2004: 2)

Barreiro (2004) señala que otra de las respuestas que ha ofrecido la teoría social sobre los procesos de difusión de la moda sostiene una postura algo diferente. En las sociedades capitalistas desarrolladas, tras el efecto de la producción en serie, pero también de la comunicación de masas y de la creciente movilidad social, la referencia para las innovaciones de todo tipo ya no son las elites económicas, sino más bien las clases medias. Para esta perspectiva teórica, los sectores medios serían verdaderamente innovadores y aquellos que asumen el rol protagónico en la vida económica contemporánea. Dada su ubicación en la estructura social, la moda se difundiría entonces tanto para "arriba" como para "abajo" en la pirámide estratificacional. A la luz de esta teoría, la sociedad de masas o sociedad de consumo se presenta como una sociedad sumamente móvil, dinámica y hasta incluso con tendencias igualitarias. Se considera que la felicidad es algo que se torna visible y se obje- 
tiva en los bienes de consumo, especialmente en una serie de objetos y signos ostensibles. Esta perspectiva teórica, conocida como la visión pluralista de los modelos de difusión, es sostenida por autores tales como Ragone (1986), Konig (1972) y Katz \& Lazarsfeld (1970). Todos ellos acuerdan que los consumos asumen un rango de innovadores nacen en una zona intermedia o "mercado medio", y no en las zonas de más altos ingresos. Wieswede (1971) sostiene que, por lo tanto, el modelo puede ser conocido como "de virulencia", en tanto que la difusión de la moda se daría así por contagio.

El modelo de difusión vertical de la moda ha sido duramente criticado por varios especialistas del tema. Lipovetsky (1990) ha sido uno de ellos. Para este autor, no debería hablarse de un régimen de difusión vertical de la moda, sino más bien de difusión horizontal. A los ojos del autor, el modelo piramidal por el cual los artículos de la moda son pasibles de ser difundidos desde los estratos superiores hacia los inferiores de manera vertical no aplica en un sentido global. Ciertamente, en sus orígenes, la moda ha sido un factor de distinción social. El vestido implicaba ya por sí mismo la ubicación de una persona en una determinada categoría social, y asimismo, determinaba su pertenencia a una clase social específica. No obstante, Lipovetsky advierte que con el surgimiento del "pret a porter" y el fin de las tendencias de temporadas unificadas, puede verse el fin del dirigismo disciplinario de la moda. Surgiría de tal modo una cierta multiplicidad estética. En términos del autor, no puede hablarse de "moda", sino más bien de "modas"; la idea del término en plural refiere entonces a la existencia de una multiplicidad de modas que coexisten y que adquieren similar legitimidad ante el conjunto de consumidores. Ante este fenómeno de fragmentación, es posible entonces notar ciertas consecuencias importantes. Por un lado, es posible advertir una mayor autonomía de los consumidores ante la aparición de las novedades. Según Lipovetsky, en el sistema anterior, ante la aparición de un artículo nuevo de moda, el consumidor debía hacerse del mismo lo antes posible; en la actualidad, las novedades presentadas por la moda deben ser entendidas como meras "indicaciones". Ya no existiría, por lo tanto, esa correspondencia entre la innovación y la adquisición, en tanto que el público que consume los nuevos artículos se han liberado de la fascinación que les provocaba antes la adhesión a las tendencias de los grandes diseñadores. La asimilación de las novedades es realizada a un ritmo distinto, propio. Por otro lado, tal como afirma el sociólogo francés, en caso de la inexistencia de una moda única, sino más bien de modas múltiples, "el look funciona a la carta" (Lipovetsky, 1990: 161). Esto significa que las mujeres y varones ciertamente siguen la moda, pero lo hacen de una manera más libre y personal. Incorporan aquellos artículos novedosos por cuestiones de gusto, y no de moda. El carácter mimético de la moda, tan bien resaltado en la obra simmeliana, ya no es absoluto; por el contrario, es posible hablar de un mimetismo optativo.

Otro fenómeno que revisa Lipovetsky es la disminución del símbolo jerárquico que supone la moda, versus la comodidad, funcionalidad o placer. El uso de determinado vestido o artículo no busca principalmente hacer alarde de la pertenencia a una clase social, sino más bien a un gusto o una necesidad de comodidad. Es posible pensar como ejemplo el uso de corsé en las mujeres. Para la época de esplendor de esta prenda, la utilización del mismo suponía la pertenencia a la clase pudiente. En la actualidad es casi impensable encontrar una mujer que renuncie a la comodidad y al bienestar físico diario o cotidiano simplemente por demostrar señales de pertenencia a la clase alta. Para Barreiro, "se pasa 
de un status-símbolo a un estilo-símbolo" (Barreiro, 2004: 5). Lipovetsky critica profundamente a Bourdieu y Braudillard, dado que ellos han olvidado ver los cambios que se evidencian en el nuevo tipo de regulación social que tiene por base principal a la seducción individual y estética.

La teoría del "filtrado descendente" también ha sido objeto de críticas por parte de otros pensadores. Braham (1997) considera que en la época actual no es posible considerar a la alta costura como la fuente de innovación principal en el sistema de la moda. Esto se debe principalmente a la existencia de grupos económicos sumamente poderosos que han dedicado sus esfuerzos a la industria de la moda. Estas grandes firmas han desdibujado la línea entre alta costura y la "moda de la calle", en tanto que incorporan elementos de las colecciones de los diseñadores reconocidos y los hacen asequibles para el público en general. Por otro lado, Braham también sostiene que el cambio de la moda no sólo se da en el sentido descendente (las clases altas influyen sobre las formas de vestir de las clases bajas) sino también a la inversa. Es posible advertir que en numerosas ocasiones las clases bajas pueden ser tomadas como modelos de referencia.

Frente a estas posturas, también es necesario mencionar la diseñada por Squicciarino (1990), para quien el modelo de difusión de la moda es el "modelo de marionetas". Tal modelo supone que, en sociedades de consumo maduras subsiste una relación piramidal disfrazada entre las clases sociales. En forma oculta, velada, y por medio de los medios masivos de comunicación, se "sugiere" a las clases inferiores modelos de comportamiento bajo el esquema "consumo-dependencia". En la visión de este sociólogo, cuanto mayor sea la emisión de pautas publicitarias que alienten un determinado consumo, mayor es la probabilidad de que las masas sean "manipuladas por los hilos del poder económico". (Squicciarino, 1990, p. 166)

Baudrillard (1974) sostiene que ningún objeto de consumo logra emerger de manera espontánea del consumidor básico (perteneciente a la clase baja) sin antes aparecer en el conjunto de bienes y/o servicios de las élites económicas. En este sentido, el consumo de objeto de la moda se filtraría en sentido descendente siempre que se logre mantener las distancias por medio de un conjunto de signos claramente visibles. A los ojos de este autor, esta forma de operación se evidencia en términos de tiempo: las necesidades de las clases medias siempre aparecen con cierta distancia temporal respecto de las clases superiores.

Más allá de las exposiciones presentadas (Barreiro, 2004), las cuales ciertamente son ricas en sus conceptualizaciones y poseen cierto carácter explicativo sobre el fenómeno de la moda, advertimos algunos problemas con relación a ellas.

Las teorías precedentes carecen de cierta "meticulosidad conceptual", tanto que las referencias a las clases sociales no siempre son del todo precisas. En particular, por la laxidad con la cual es utilizado permanentemente el término. Por otro lado, la referencia a conceptos tales como "clases pudientes", "clases altas", etcétera, sólo evidencia la falta de claridad conceptual y la carencia de una teoría mayor que logre sustentar de manera correcta tal referencia. Si bien es posible que muchas de las teorías analizadas sean efectivas para señalar las formas de difusión de un fenómeno tan esquivo como la moda, creemos que no logran explicitar de manera clara el código que utilizan. Siguiendo entonces el análisis de Dantas, creemos que las teorías anteriores carecen de un código explícito que permitiera discutir en profundidad algunas de las conclusiones a las cuales arriban sus pensadores. 
En la primera sección de este artículo hemos analizado algunas de las teorías más relevantes de la tradición sociológica con relación a la moda. No obstante, sería ingenuo pensar que la moda sólo es un "itinerario social" o un "fenómeno social" sin más. Por el contrario, creemos que la moda es el producto de una cadena de actividades industriales, económicas y culturales.

Según Barreiro:

Lo que distingue el código de la moda es que ha de pasar por el filtro de la industria de la moda, de modo que las modificaciones del código presentadas en las pasarelas se exponen a ser rechazadas por una serie de publicistas y periodistas de la moda, pero también los fabricantes y los compradores. La moda no es sólo cultura, sino también industria. (Barreiro, 2004, p. 7)

Ciertamente, muchos estudios sociológicos sobre el fenómeno de la moda han carecido de la perspectiva económica, centrando su atención tal vez en otros aspectos, pero "olvidando" sin dudas aquel que resulta central para un estudio omnicomprensivo de un fenómeno social de elevadísima complejidad. Para comprender la moda es menester, por lo tanto, mostrar también los procesos socioeconómicos que permiten el paso del diseño al artículo colocado en la vidriera de una tienda.

\section{Capitalismo informacional. Algunos elementos conceptuales}

Hacia la década del '90 es posible encontrar el debate que emerge sobre el "capitalismo de fin de siglo", y los análisis que devienen sobre su naturaleza y desarrollo. De esta manera, varios estudios hacen hincapié sobre el pasaje hacia una Tercera Revolución Industrial Informacional, y el uso de las tecnologías de la información y comunicación (TICs) adquiere especial relevancia, tal vez dejando en un segundo plano el análisis sobre los distintos sistemas de organización del trabajo. Muchas de las falencias de dichos análisis radican en su visión estrictamente nacional, no advirtiendo que tales patrones de desarrollo deben ser analizados en el marco de una nueva división internacional informacional del trabajo (NIIDT) (Roldán, 2000). Es decir, es necesario dar cuenta que la producción de conocimiento científico y técnico como así también de tecnologías, se concentran en ciertas áreas de la economía mundial, localizables en los países centrales de economías industriales avanzadas. En la actualidad, la brecha entre países centrales y países subdesarrollados o periféricos con relación a este tema se han acentuado aún más.

Dentro de la multiplicada de enfoques disponibles para el análisis de la producción y el trabajo humano, se ha seleccionado aquella propuesta elaborada por la Escuela de la Economía Política Crítica, dado que se considera es la que mejor articula tópicos de especial relevancia tales como información, TICs, distintas configuraciones espacio-temporales, conocimiento, al mismo que integra también la preocupación por la organización del trabajo y el vínculo institucional relacionado con el desarrollo del modo de producción capitalista. Ya ha sido mencionado previamente el advenimiento de la Tercera Revolución Industrial Informacional. Para poder dar cuenta de las particularidades de la misma, se hará referen- 
cia al bagaje teórico legado por Dantas $(2002,1999)$, quien en distintas obras ha sabido re-elaborar o resignificar la teoría de la información de manera tal que resulte aplicable al estudio del trabajo humano y la valorización del capital. Es conveniente considera que, para Dantas, el capitalismo de los países centrales, ya desde la Segunda Revolución Industrial, adquiere características "más informacionales".

En este sentido, Dantas entiende que todo proceso de trabajo humano es informacional, en tanto que el trabajo contempla la necesidad de recibir, procesar, registrar o transmitir información. Evidentemente, en todo proceso de trabajo existe un sustrato físico o material, que se encuentra sujeto a las leyes físicas propias de la termodinámica. No obstante, el procesamiento de la información supone el mismo tipo de sujeción a tales leyes, en tanto que la acción de emitir, procesar, y registrar información, con acuerdo a ciertas significaciones culturales, exige de un cuerpo físico que realice ciertas acciones de transformación de la materia. Indudablemente, la transmisión de información no sólo se relaciona a un hecho de capacidad, sino también de voluntad: es menester contar con otro sujeto que esté dispuesto a recibir la información producida por el agente emisor. La información supone, por tanto, un proceso bidireccional y la utilización de ciertos códigos compartidos que ofrecen orientaciones para la acción. En tal sentido, la aproximación de Dantas resalta la idea de que la información es resultado del trabajo vivo, y no la mera transmisión de un "algo", ya sean datos o conocimiento, resultado de un trabajo pasado. Muchas de las teorizaciones sobre la información caen en el grave error de identificar a los productos informáticos como algo inmaterial. Desde la perspectiva de Dantas, no existe nada más alejado de esto. Por el contrario, toda información es resultado del trabajo vivo de seres humanos, y existe en tanto acontecen transformaciones físicas y químicas. La particularidad de la información consiste en que no reside en nadie en particular (ni en su emisor o su receptor); se "localiza" más bien en la interacción que de ellos surge. Las teorizaciones sobre la teoría de la información que propone Dantas resultan de especial utilidad para dar cuenta que la comunicación es parte integral del proceso de trabajo.

Teniendo en cuenta las consideraciones generales precedentes, es posible hablar de una Tercera Revolución Industrial Informacional, al menos con ciertas salvedades. El mismo Dantas identifica que el uso generalizado de las TICs y del trabajo informacional ya es localizable durante los años ' 40 y '50 del siglo XX en los Estados Unidos, durante la llamada era fordista. Por tal motivo, el uso de este tipo de tecnología no es algo nuevo ni propio de los últimos veinte años. En tal sentido, la evolución socio-económica del presente es sólo una continuación de una pauta iniciada ya en la Segunda Revolución Industrial, es decir, la introducción de la ciencia y la tecnología en el proceso productivo. Lo que sí podría calificarse de novedoso es que las industrias líderes de la Tercera Revolución Industrial Informacional se encuentran completamente determinadas por diversas teorías científicas, ya sea por el procesamiento de información, la comunicación global (informática, telecomunicaciones) o aún las industrias culturales. Las actividades propias del proceso productivo supone la existencia de trabajadores calificados; todo trabajo que no requiera tal calificación, es dejado en manos de empleados subcontratados y ejercido en países periféricos. (Castells, 1997)

Por otro lado, las TICs suponen también la presentación de ciertos desafíos que se le presentan a las grandes construcciones teóricas que han dado cuenta del proceso productivo. 
Su permanente crecimiento y desarrollo han dejado atrás las más visionarias formulaciones respecto de sus alcances. Por tal motivo, el creciente uso de TICs permite la unificación de distintos procesos de trabajo, facilitando a la vez las condiciones para el surgimiento de monopolios. Sirva de ejemplo la industria de la informática.

Con el creciente uso de las TICs, mucho o gran parte del trabajo informacional que antes dependía exclusivamente del trabajo vivo ahora es delegado a las máquinas. De este manera, ordenadores de enorme capacidad de procesamiento de información (llamado "trabajo muerto") reemplazan las operaciones antes realizada por el trabajo humano "vivo". Ciertamente, estas actividades de remplazo se relacionan con aquellas actividades de carácter redundantes, rutinarias o repetitivas. $\mathrm{Al}$ inicio de este apartado se mencionaba casi al pasar las categorías espacio-tiempo, sin haber profundizado en ellas. Tal como afirma Harvey (1998), durante el desarrollo de la Tercera Revolución Industrial Informacional, existen buenas razones, tanto políticas como económicas, para el uso generalizado de las TICs, hecho que conduce a una intensificación del tiempo de trabajo, desde la perspectiva de este pensador. Esta consecuente intensificación conlleva a ahorros en la circulación, y por ende, a una creciente valorización en la esfera de la circulación del capital, tanto a nivel nacional como internacional.

Por otro lado, es posible entender que tal intensificación temporal coadyuva a una conformación de una nueva división internacional informacional del trabajo, en tanto que, tal como ha sido afirmado previamente, el conocimiento científico y tecnológico es concentrado en unos pocos países desarrollados o centrales, mientras que los países en desarrollo o periféricos son dejados de lado. Siguiendo a Roldán (2005), existen al menos dos "senderos de imposición" de la configuración espacio-temporal intensificada. El primero de ellos, llamado "sendero directo", señala que las TICs permiten a las empresas operar en forma de red y facilitan el hecho de la subcontratación internacional. Dado que el procesamiento de la información se ve facilitado por el uso generalizado de las TICs, estas empresas producen un bien completo trabajando como una unidad en tiempo real. No obstante, las actividades de creación, innovación e investigación científica y tecnológica se reservan para los países centrales mientras que las actividades rutinarias, que requieren poca calificación para la realización de operaciones repetitivas, son dejadas en las manos de empresas subcontratadas en los países periféricos. Claramente, resulta visible la división internacional informacional del trabajo que de aquí deriva. El segundo sendero de imposición es el llamado "sendero indirecto", representado por la obstaculización o impedimento de una configuración espacio-temporal intensificada y autónoma en las economías periféricas. Los acuerdos internacionales y pactos regionales tales como NAFTA o MERCOSUR resulta un ejemplo de ello. Tal como afirma Roldán (2005), ambos senderos no son circuitos paralelos o desarticulados, sino por el contrario, una dimensión necesaria de la construcción de la nueva división internacional informacional del trabajo.

\section{Moda y producción. Uso de TICs en la industria de la moda en la actualidad}

La economía a escala mundial tiene, entonces, dos características principales. Por un lado, es una economía donde la productividad y la competitividad de las unidades o agentes, ya 
sean empresas, regiones o naciones, dependen de la capacidad de dichas unidades para generar, procesar y aplicar con eficiencia la información. Asimismo, esta economía mundial adquiere una característica global, en tanto que la producción, el consumo y la circulación, así como también sus componentes, tales como capital, mano de obra, materias primas, tecnología y mercados, están organizados a escala global.

Según algunos autores (Singleton, 2000), las empresas de confección textil tienen una existencia efímera, lo cual lleva a que las mismas sean remplazadas por nuevas empresas en un tiempo relativamente corto. En cierto sentido, es posible coincidir con esta postura, en tanto que muchas empresas textiles se enfrentan al desafío de mantener la competitividad, lo cual ha producido severos cambios en la estructura internacional del sector. En la actualidad, es posible ver como ciertos países que antes lideraban la exportación de estas mercaderías ahora han quedado relegados frente al avance de otros.

No obstante, también es posible ver como ciertas firmas que antes tenían una actividad meramente local, ahora se encuentran sumamente diversificadas y tienen presencia en una multiplicidad de países, conformándose como poderosos "holdings". Ciertas firmas que antes tenían una estructura familiar, modesta, ahora se presentan como poderosas firmas que lideran los cambios en el sector. En la jerga empresarial, estas firmas son denominadas "killers".

En las últimas dos décadas el sector de la industria textil ha cambiado significativamente. Los nombres de las empresas que lideran el mercado ya no son los mismos que los de veinte años atrás, así como tampoco lo es el tamaño de las mismas. También se ha modificado drásticamente el volumen de sus operaciones y el lugar de residencia de sus casas matrices. Siguiendo a Barreiro en este análisis, es posible advertir que aquellas firmas que lideran el mercado son relativamente nuevas, o bien han asumido su forma actual desde hace pocos años.

Una de las firmas líderes del mercado, la empresa norteamericana GAP, tuvo su origen en el año 1969, a partir de la creación de sus dueños, Don y Doris Fisher, quienes eran dos desconocidos en el momento de la fundación de la naciente compañía. En el año 1954 se funda en New Haven la primera de las tiendas de Ann Taylor, una diseñadora de ropa femenina que, años después, también sería líder del mercado. La empresa The Limited fue creada en 1963, también en Estados Unidos, y la compañía suiza Vogele sólo lo fue ocho años antes. No obstante, existen empresas que pueden ser calificadas como killers de muy reciente creación, tales como la compañía británica Next, que ha sido fundada en 1982 o la española Mango, en el año 1987.

No obstante, no todos los "killers" de la industria de la moda son tan jóvenes. Compañías tales como Abercrombie \& Fish, de Estados Unidos, la empresa italiana Benetton, la holandesa C\&A o la empresa sueca Hennes \& Mauritz (H\&M) tienen sus orígenes mucho tiempo atrás, si bien se han comportado como verdaderos "killers" de la industria sólo recién a partir de los años '70 y '80, cuando ciertas formas de organización empresarial fue adaptada a los tiempos que corrían. También dentro de este grupo se ubica el Grupo Inditex, más conocido como Zara, quien ha modificado sustancialmente su forma de ofrecer los productos al mercado, pasando de una acción de venta sólo a nivel local, a un monstruo empresarial con presencia en más de 33 países de todo el mundo.

Como es evidente, la mayoría de estos "killers" tienen sus orígenes en el polo más desa- 
rrollado de la economía capitalista. La mayoría de estas compañías, si bien con presencia internacional, tienen sus casas matrices en Estados Unidos y Europa. La fuerte presencia internacional puede ser explicada, a grandes rasgos, por la apertura de la economía, la fuerte homogeneización de las preferencias de los consumos de masas y, especialmente, por la rápida difusión de las tecnologías de la información (TICs), en particular aquellas relacionadas con la transferencia y procesamiento de la información.

Este conjunto de empresas (el listado ciertamente no es exhaustivo, pero si claramente demostrativo del tipo de empresa textil) necesita un conjunto de dispositivos organizativos que les permita enfrentar los desafíos de la economía mundializada.

Una de las tendencias más importantes que pueden identificarse en la evolución organizativa del sector textil es la transición de la producción en serie a la producción flexible. El abandono de la producción en serie puede explicarse por varios motivos. Por un lado, la demanda de los bienes se tornó casi impredecible tanto en cantidad como calidad. Asimismo los mercados se diversificaron en todo el mundo lo que dificultaba su control. Por otro lado, el ritmo vertiginoso que asume el cambio tecnológico provocó que el equipo de producción de cometido único se volviera virtualmente obsoleto. Ante todos estos factores, el sistema de producción en serie parecía ser demasiado rígido y ende costoso para enfrentar todos estos desafíos a los que la nueva economía lo enfrentaba. Una forma de resolver estos potenciales problemas fue asumir una producción flexible. Con la ayuda de las tecnologías de la información y, especialmente, con la asistencia de la computadora, ahora es posible producir menores cantidades de productos y con características más individualizadas que con la producción en serie. La producción flexible demostró ser sumamente eficaz para dar respuesta a los cambiantes gustos de los consumidores. Ante nuevos requerimientos de las personas con relación a los productos que la empresa coloca en el mercado, la producción flexible permite a las empresas diversificar su línea productiva con el objetivo de dar respuesta rápida y certera. Las TICs facilitan, entonces, que las anteriores cadenas de montaje características de las grandes empresas se conviertan en unidades de producción más sencillas de programar con el objetivo de ser sensibles a las variaciones del mercado local o internacional. Estas variaciones del mercado pueden ser tanto propias del producto (cambios sobre los gustos de los consumidores sobre determinados artículos) o bien cambios en los insumos tecnológicos, lo que otorgaría una flexibilidad extra al proceso de producción del artículo.

Barreiro afirma que:

Lo que hace posible esta "producción flexible" deriva en parte de la elevada integración vertical. En el sector existen varias modalidades de integración: la predominante, que incluye los procesos de diseño y comercialización (...), pero deja fuera la fabricación, que se sub-contrata a otras sociedades (en muchos casos de actividad sumergida o de países asiáticos, donde no existe reglamentación laboral); y el modelo Benetton, que integra los procesos de diseño y fabricación, pero la comercialización se realiza al por mayor a través de franquicias y sólo raramente por medio de joint ventures o tiendas propias. (Barreiro, 2004, p. 11) 
Existiría también un tercer modelo, aquel liderado por las tiendas Zara, el cual consiste en actuar mediante un modelo integrado desde el diseño, el aprovisionamiento de las materias primas, la producción, la red logística y las tiendas. Todos estos factores tienen un grado de pertenencia al grupo que varia entre un $40 \%$ y llega hasta un $92 \%$ en algunos otros, tal como el caso de la propiedad de las tiendas.

Uno de los elementos que otorga flexibilidad a las empresas textiles es la utilización casi generalizada del sistema de sub-contratación, ya sea en países desarrollados o en desarrollo (aunque con mayor incidencia en estos últimos), dado que permite aumentar o disminuir la escala de la producción en función del comportamiento del mercado. No obstante, este tipo de práctica trae aparejada efectos sociales "indeseables", que afectan a la imagen corporativa de estas empresas textiles. El conocimiento público de algunas prácticas de estas grandes corporaciones ha supuesto elevadísimos costos, trayendo aparejados serios problemas de imagen que, a pesar de los bajos costos salariales, los mismos no son compensados por la disminución en la facturación general de la empresa. En este sentido, los ejemplos sobran. Tal vez uno de los casos más resonantes ha sido las campañas boicoteando a la marca Nike, a partir del conocimiento de que dicha empresa utilizaba trabajo infantil en una de las empresas sub-contratadas en Indonesia. Otro caso similar sucedió con la marca C\&A, quien fue acusada de utilizar mano de obra en condiciones de suma precariedad, alcanzando más de 13 mil empleados quienes desarrollaban sus tareas en condiciones infrahumanas.

El modelo de producción flexible utilizado en la industria textil basa su eficacia a partir de adoptar el modelo "Just in time" (JIT), el cual consiste en el establecimiento de pequeñas cadenas de producción independientes, lo cual otorga mayor facilidad para modificar sobre la marcha la producción. Este hecho otorga una mayor capacidad para adaptarse a los cambios de la demanda de los artículos. El modelo JIT también permite para estas grandes industrias textiles ordenar los datos sobre las ventas globales entre fabricantes y minoristas, con lo cual es posible operar con niveles de inventario mínimos. Todo esto se encuentra asimismo maximizado por la utilización de las TICs, las cuales permiten conocer en tiempo real una enorme cantidad de información, y luego de su procesamiento, tomar decisiones sobre cambios de los artículos producidos, por ejemplo. Dado el gusto siempre cambiante de los consumidores, las industrias textiles basan su producción en pedidos firmes de los minoristas, con el objetivo de disminuir el exceso de artículos. Ciertamente, sólo con la utilización de las TICs es posible maximizar los beneficios de esta organización productiva. La casa central de cualquier industria textil cuenta con información detallada, tal como los artículos que se venden, la preferencia de colores, las tallas de las prendas más solicitadas y muchos otros datos que, gracias a la utilización de poderosas redes informáticas, permite a la compañía decidir con rapidez y flexibilidad a la demanda de los consumidores.

La fabricación de prendas siempre ha sido un tema que ha supuesto el mayor desafío para las grandes corporaciones textiles. Hace unos cincuenta años, una colección de prendas necesitaba al menos un ciclo de producción de 300 días para ver la luz en las vitrinas de los negocios. Obviamente, en la época actual esto supone un riesgo elevadísimo, el cual la mayoría de las grandes corporaciones no están dispuestas a asumir. Por el contrario actualmente está instalado un modelo distinto, el cual supone la colocación de una colección 
completa, la cual es fabricada en países sub-desarrollados de Asia o África, con muy bajos costos laborales, y vendida en los países centrales (y también en vías de desarrollo o emergentes). Aquellas prendas que no son posibles vender, la compañía las coloca en venta a precios mucho más bajos (aunque igualmente con un margen de ganancia significativo) que lo que es conocido como las "rebajas". Las "liquidaciones" o "rebajas" han demostrado ser sumamente efectivas para las compañías textiles en tanto que logran el cometido de vender el stock remanente de las prendas de una colección antes del lanzamiento de la próxima.

Por otro lado, un modelo que ha demostrado enorme éxito es el llevado adelante por la gigantesca Zara, para quien las colecciones de cada temporada no suponen una renovación completa y absoluta de su stock, sino más bien la colocación de una cantidad de prendas mínimas con relación al total que dispone para la venta. El 60\% de las prendas en venta corresponden a lo que se denomina "básicos", es decir, prendas que por sus características, se encuentran presentes en todas las colecciones, y por ello, "no pasan de moda". Dentro de los básicos se encuentran remeras y pantalones de colores neutros, trajes sastre o bien accesorios tales como cinturones o pañuelos. Por otro lado, el $40 \%$ restante de la producción es realizada bajo el modelo Just in Time. La asistencia de las TICs es de fundamental importancia para la empresa. Con dicho modelo y tales herramientas, la compañía es capaz de colocar en el mercado más de quince mil artículos distintos, sin contar tallas y colores, susceptibles de ser aceptado en el cambiante gusto de los consumidores de moda. La ayuda prestada por las TICs se revela como vital para que dichos artículos coincidan a tiempo con el gusto de los consumidores.

De igual modo, el sistema de producción textil propone una oferta diversificada en función de las características del mercado. Muchas de las grandes corporaciones textiles han adoptado una oferta diversificada y, en consecuencia, han acrecentado enormemente sus ganancias. Las que no han adoptado esta solución, tales como C\&A, reconocen menores réditos económicos en sus estados de resultados que el resto. Por el contrario, algunas grandes compañías, tales como el grupo textil Inditex (dueño, entre muchas otras marcas, de la conocidísima Zara) ofrece hasta cinco marcas distintas para satisfacer las necesidades de un mercado sumamente diverso, tanto en gustos como en posibilidades económicas. Algunas de sus marcas se dirigen a un público de nivel socio-económico medio, cuyo foco principal es "vestir" a la familia completa. En tal sentido, sus colecciones de prenda incluyen ropa diseñada especialmente para la madre, el padre y los niños. Toda la familia encuentra en sus tiendas qué usar. En cambio, otras marcas del mismo grupo dirigen su atención a jóvenes mujeres que se encuentran pendientes de la ropa de alta costura, y encuentran en las prendas que ofrece la compañía una "traducción" de dichas prendas en ropa "casual". Ejemplo de ello es también el tipo de prendas ofrecidas por la empresa H\&M, quien ofrece sus colecciones de prét-a-porter diseñadas por reconocidos diseñadores de alta costura o personalidades vinculadas con la moda. Karl Lagerfeld o Madonna han sido alguno de los diseñadores encargados de elaborar colecciones de prendas seleccionadas. Por supuesto, los precios de estas prendas son accesibles a un público amplio y general.

Todas estas distintas estrategias sólo son posibles gracias al conocimiento profundo que estas compañías tienen de las preferencias de los consumidores. Existen muchas vías por las cuales las tiendas acceden a esta información. Por un lado, el conocimiento de las nuevas tendencias de diseño que surge a partir de las colecciones que son desplegadas en las pasa- 
relas internacionales por los grandes diseñadores. Asimismo, las grandes compañías cuentan con una serie de informantes que frecuentan lugares "de moda", tales como discotecas, bares o restaurantes; todos ellos son espacios donde recaban información de lo que "se usa". No obstante, la época actual cuenta con un elemento propio y central de la economía informacional: la apropiación de las TICs por parte de las grandes corporaciones textiles son sin dudas el elemento más importante para conocer en tiempo real el gusto de los consumidores, los cuales, la mayoría de las veces no se encuentran en el mismo espacio físico. Los mismos empleados de las tiendas, ubicadas en zonas remotas unas de otras, transmiten en tiempo real y a increíbles bajos costos, a la casa central, información detalladas sobre colores, tallas, prendas y demás. Esta información, una vez procesada, es retransmitida a los centros de producción de las compañías y se actúa en consecuencia. (Castells, 1997) Por otro lado, las grandes corporaciones no sólo se preocupan de satisfacer a sus clientes en términos de una oferta de producto que se adecue a sus gustos y preferencias. Una vez que se considera que tal objetivo está cumplido, las grandes tiendas deben asegurarse que el cliente satisfecho se convierta en cliente nuevamente, y así sucesivamente. Es decir, estas compañías invierten enormes sumas de dinero en campañas de fidelización para asegurarse que los compradores vuelvan a comprar. Los informes sobre esas inversiones en publicidad y campañas de fidelización pueden resultar sorprendentes. Compañías tales como GAP y H\&M utilizan la publicidad directa en los medios masivos de comunicación, y gastan alrededor del $5 \%$ de sus ingresos en publicidad. El promedio del sector es de un 3,5\%, según afirma Barreiro (2004), aunque no todas las compañías invierten de similar modo. Zara, por ejemplo, sólo dedica un $0,3 \%$ de sus ingresos a publicidad, dado que considera que tal modo no justifica el retorno de inversión. Sólo lo hace en los casos de sus "rebajas" estacionales, y de manera sumamente discreta, comparada con otros.

El caso que se encuentra en las antípodas de las acciones de Zara es, ciertamente, Benetton. El gigante italiano es conocido por sus agresivas campañas de publicidad. El hecho de no utilizar la publicidad directa en el marco de la sociedad industrial informacional no supone el abandono de las estrategias de promoción de las marcas. Zara es el ejemplo más claro. Si bien no utiliza sus recursos para llevar adelante campañas publicitarias muy fuertes, la estrategia utilizada es por medio del "boca a boca". Para ello, la compañía concentra sus esfuerzos en instalar tiendas en las ciudades principales, en las zonas más céntricas y en las esquinas más concurridas. Sus vidrieras, al mismo tiempo, son llamativas y focalizan la atención del transeúnte. No obstante, es menester señalar que el "boca a boca" se ha resignificado durante los últimos cincuenta años. En la actualidad, las personas acceden a distintos medios de comunicación, muchos de ellos virtuales (redes sociales, por ejemplo) que ejercen la poderosa tarea de conectar a las personas en lugares muy remotos. Zara, al igual que otros, sabe que sus clientes se encuentran interconectados en una sociedad donde las TICs se encuentran por todos lados. Si bien sus campañas de publicidad no son de alcance mundial, es posible imaginar como un cliente satisfecho hace un comentario a su amigo, ubicado en otra ciudad o aún otro país, por medio de un correo electrónico y vía una comunicación telefónica. En este caso, el boca a boca resulta aún más efectivo de lo que era antaño.

Por otro lado, no toda publicidad debe referir a los productos que la compañía comercializa específicamente. Ya lo afirmaba Lipovetsky (2003), cuando decía que la época actual 
es la era del "marketing de la solidaridad". Cada vez más, las grandes tiendas orientan sus esfuerzos hacia una publicidad que demuestre su adhesión a principios éticos y morales con los cuales la mayoría de la población se sienta comprometido. Todo ello con un único fin: mejorar la imagen corporativa de las grandes empresas.

Tal vez el primero en orientar sus esfuerzos hacia esta estrategia ha sido Benetton, para quien la idea central de su mensaje ha sido el antirracismo y la tolerancia a la diferencia. ¿Cómo olvidar las publicidades de niños orientales, africanos, latinos y caucásicos, todos ellos vestidos con los coloridos sweaters de Benetton, en línea y tomados de la mano, con el slogan "United Colors of Benetton"? El mensaje, el cual admite dos niveles de lectura, hacía clara referencia a la idea de la tolerancia a las diferencias raciales. Con ello, Benetton buscó, y en cierta medida, lo logró, generar una imagen corporativa que resultara atractiva a la masa de consumidores de sus productos. Esta buena imagen corporativa se convierte así en un nuevo factor de competitividad. Todo esto, en algún punto, entra en contradicción con algunas denuncias recibidas años después sobre el uso de trabajo en condiciones infrahumanas, que han dañado esa imagen "responsable" construida.

\section{Algunas reflexiones a modo de conclusión}

El artículo precedente ha sido un intento por mostrar las características que asume la producción de las prendas de vestir "de moda" durante la era de la Tercera Revolución Industrial Informacional. Con ello, no se ha pretendido realizar una revisión exhaustiva del tema tratado, sino más bien esbozar una presentación de carácter exploratorio que permite identificar nuevas problemáticas y tópicos relevantes para la realización de futuras indagaciones.

Debe quedar claro que no es posible sostener que la producción industrial durante esta Tercera Revolución Industrial Informacional supone un abandono de la idea de la industria frente a la idea de la información. Ya ha sido señalado previamente, específicamente sobre la propuesta teórica de Dantas (1999), que toda información no puede ser considerada de modo análogo a un "dato" transmitido. Por el contrario, la información supone una transformación de la materia realizada por un sujeto vivo, motivo por el cual toda información debe entenderse como producción, y no mera transmisión. Errores de este tipo son propios de una semántica equivocada, que genera sentidos y horizontes de significación desde el cual las prácticas sociales son producidas y reproducidas (Berger y Luckmann, 2003). Asimismo, el procesamiento de la información no es algo nuevo: ya durante la etapa fordista es posible verificar la existencia de actividades de investigación en ciencia y tecnología, con sus consecuentes impactos en la producción. Lo que tal vez resulta novedoso en el época actual es el uso generalizado de las tecnologías de la información y la comunicación (TICs), que le imprimen al sistema productivo una flexibilidad nueva y modifica en forma sustancial también las dinámicas de valorización del capital en el circuito de la circulación (Castells, 1997), por medio del establecimiento de una nueva división internacional informacional del trabajo (Roldán, 2005). De esta manera, las actividades creativas son reservadas para las casas matrices de las grandes compañías localizadas en los países centrales, mientras que las actividades redundantes y repetitivas son dejadas 
en manos de sus filiales o subcontratistas ubicados en países periféricos (Castells, 1997). Esta dinámica de localización espacial y división de tareas sólo conduce a profundizar una diferenciación sobre las posibilidades de desarrollo de los diferentes Estados.

En este sentido, muchos han sido los debates sobre la idea de desarrollo de una sociedad. En este trabajo también se ha seguido a Jaggar (1983) y su concepción de la sociedad buena, es decir, una concepción que avanza sobre la ética y la pregunta fundamental de la filosofía política. En Roldán (2000), la pregunta por el desarrollo encuentra su respuesta en aquello que es "concebido como dinámica de construcción de contextos que garanticen el ejercicio de los derechos económicos sociales, culturales, civiles y políticos como dimensiones indivisibles de los derechos humanos" (Roldán, 2000, p. 11). Ciertamente este artículo no avanza en la respuesta a tal interrogante, pero es menester que tal preocupación sea un objeto de reflexión constante por la comunidad académica y científica abocada al análisis de los procesos productivos. La interpelación necesaria desde la organización del trabajo en la industria de la moda se presenta como una casi obligación para todo aquel investigador comprometido.

El artículo presenta, al mismo tiempo, información relevante sobre las conceptualizaciones de la moda que son usualmente utilizadas por parte de la comunidad de científicos y especialistas abocados a una mirada sociológica del fenómeno. Tales teorías conforman el código compartido, aunque ciertamente en muchas ocasiones se traten de teorías en franca competencia. Pensar la moda exige, al mismo tiempo, pensar el soporte de la misma. En este sentido, la reflexión sociológica del cuerpo ha sido introducida como mirada necesaria para dar cuenta del objeto de la acción de mostrar y cubrir de las prendas de vestir. Las distintas concepciones presentadas han sido de utilidad para comprender la complejidad de un tema que durante mucho tiempo había sido olvidado en la reflexión sociológica.

Los aportes de la Teoría de la Economía Política Crítica, en sus revisiones más contemporáneas, han sido recuperados con el objeto de aprehender las características sobresalientes de la Tercera Revolución Industrial Informacional. En este marco, han sido también presentadas las características de la producción de prendas de vestir por las grandes compañías transnacionales, con la pretensión de dar cuenta de las especificidades de la producción industrial informacional en una época de capitalismo mundializado. Se ha visto como el uso generalizado de TICs ha modificado la forma de producción, que pasa de un modelo fordista hacia un modelo más flexible, basado en el formato Just in Time. Todo ello ha sido realizado, en virtud del ejercicio de la imaginación sociológica, con el objetivo de revisar la actual configuración de la producción en el ámbito de la moda. Por ello, una indagación que se proponga profundizar en esta temática requiere la utilización de categorías conceptuales adaptadas a las condiciones socio-estructurales actuales, al mismo tiempo que una revisión de la tradición sociológica más clásica, que ya ha producido una caja de herramientas sumamente valiosa para interpelar a la realidad social y los hechos sociales que la conforman.

\section{Bibliografía}

Barthes, R. (2003). El sistema de la moda y otros escritos. Buenos Aires: Paidós. 
Bauman, Z. (2010). Mundo Consumo. Ética del individuo en la aldea global. Barcelona: Paidós. Berger, P. y Luckmann, T. (2006). La construcción social de la realidad. Buenos Aires: Amorrortu.

Braham, P. (1997). “Fashion: Unpacking a Culture Production”, en Du Gay, P. (Comp.). Production of Culture, Cultures of Production. Londres: Sage.

Baudrillard, J. (1974). La sociedad de consumo: sus mitos, sus estructuras. Barcelona: Plaza \& Janés.

Castells, M. (1997). La era de la información: Economía sociedad y cultura, vol. 1. Madrid: Alianza.

Croci, P. y Vitale, A. (Comps) (2000). Los cuerpos dóciles. Hacia un tratado sobre la moda. Buenos Aires: La Marca.

Dantas, M. (1999). Capitalismo na Era das Redes: trabalho, informacao e valor no ciclo da comunicacao produtiva. Rio de Janeiro: Contraponto.

Dantas, M. (2002). A lógica do capital-informacao. A fragmentacao dos monopolios e a monopolizacao de fragmentos num mundo de comunicacoes globais. Rio de Janeiro: Controponto.

Foucault, M. (2004). El nacimiento de la clínica. Una arqueología de la mirada médica. Buenos Aires: Siglo XXI.

Jaggar, A. (1983). Feminist Politics and Human Nature. Brighton: Rowman \& Allanheld.

Le Breton, D. (1995a). La sociología del cuerpo. Buenos Aires: Nueva Visión.

Le Breton, D. (1995b). Antropología del cuerpo y modernidad. Buenos Aires: Nueva Visión. Lipovetsky, G. (1990). El imperio de lo efímero. La moda y su destino en las sociedades modernas. Barcelona: Anagrama.

Lurie, A. (1981). The language of clothes. London: Hamlyn Publishing Group.

Roldán, M. (2000).¿Globalización o mundialización? Teoría y práctica de procesos productivos $y$ asimetrías de género. Buenos Aires: UNP (SJB) Delegación Zonal Trelew - FLACSO EUDEBA.

Roldán, M. (2005). Nueva División Internacional-Informacional del Trabajo (NDIIT). Configuraciones Tempo-Espaciales y organización del trabajo. Explorando algunas dimensiones clave del desarrollo ausente argentino. Madrid: Nueva Época.

Saulquin, S. (1998). "Saturación y nuevo orden en el sistema de la moda", en Ravera, R. M. (1998). Estética y Crítica. Buenos Aires: Crítica.

Saulquin, S. (1999). La moda, después. Buenos Aires: Editorial ISM.

Simmel, G. (2005). Sobre la individualidad y las formas sociales. Buenos Aires: Universidad Nacional de Quilmes.

Simmel, G. (1988). La aventura. Barcelona: Paidós.

Singleton, J. (2000). The World Textile Industry. London: Routledge.

Squicciarino, N. (1990). El vestido habla: Consideraciones psicosociológicas sobre la vestimenta. Madrid: Cátedra.

Summary: The twentieth century is a witness and the scene of many political, economic, social and cultural changes brought about by the changes in the technological and scientific level. These involve the acceleration of time and major changes in social habits and customs. 
Fashion, as a manifestation of culture, is not exempt from these changes and will be an expression of the new winds of change. With artistic movements as allies, the emergence of new actors such as women and youth in the social scene, the momentum of the mass media and the impact of globalization, among other variables, fashion acquire unthinkable dimensions; and advances and retreats, will be consolidated as an industry with its own laws and dynamics. Browse some of the scenarios of the twentieth century will be the aim of this Journal, inviting us to reflect on these hundred years that changed history.

Key words: fashion - culture - society - social transformation - art - mass media.

Resumo: $\mathrm{O}$ século XX é testemunha e cenário de múltiplas mudanças políticas, econômicas, sociais e culturais alentadas pelas transformações no plano tecnológico e científico. Estes implicam a aceleração dos tempos e, com eles, grandes transformações nos usos e costumes da sociedade. A moda, como manifestação da cultura não quedará isenta dessas transformações e será expressão dos novos ventos de mudança. Com os movimentos artísticos como aliados, a irrupção de novos atores como as mulheres e os jovens na cena social, o impulso dos meios massivos de comunicação e por impacto da globalização, entre outras variáveis, a moda vai adquirir dimensões impensadas, e com avanços e retrocessos, vai se consolidar como uma indústria com suas próprias leis e dinâmica. Percorrer parte desses cenários do século XX será o objetivo deste caderno, invitando a refletir sobre esses cem anos que mudaram a história.

Palavras chave: moda - cultura - sociedade - transformações sociais - arte - mass media. 